Original Article - Clinical Science

\title{
Prevalence and characteristics of choroidal nevi: the Australian National Eye Health Survey
}

\author{
Stuart Keel PhD, ${ }^{1}$ Jing Xie $\mathrm{PhD}^{1}{ }^{1}$ Joshua Foreman BSci(Hons) ${ }^{1,2}$ Hugh R Taylor
} FRANZCO AC ${ }^{3}$ and Mohamed Dirani PhD ${ }^{1,4}$

${ }^{1}$ Centre for Eye Research Australia, Royal Victorian Eye \& Ear Hospital, Melbourne, Australia, ${ }^{2}$ Ophthalmology, University of Melbourne, Department of Surgery, Melbourne, Australia, ${ }^{3}$ Indigenous Eye Health Unit, Melbourne School of Population and Global Health, The University of Melbourne, Melbourne, Australia, ${ }^{4}$ Singapore Eye Research Institute, Singapore National Eye Centre, Singapore.

Correspondence: Dr Stuart Keel, Level seven, Centre for Eye Research Australia, 32 Gisborne Street, East Melbourne, Victoria 3002, Australia

Email: stuart.keel@unimelb.edu.au

Short running title: Choroidal nevi in Australia

Received 20 October 2017; accepted 25 February 2018

Conflict of interest: None

Funding sources: Department of Health of the Australian Government, Novartis Australia and the Peggy and Leslie Cranbourne Foundation. In-kind support from our industry and sector partners, OPSM, Carl Zeiss, Designs for Vision, the Royal Flying Doctor Service, Optometry Australia and the Brien Holden Vision Institute. The Centre for Eye Research Australia receives Operational Infrastructure Support from the Victorian Government. The Principal Investigator, Dr Mohamed Dirani, is

This is the author manuscript accepted for publication and has undergone full peer review but has not been through the copyediting, typesetting, pagination and proofreading process, which may lead to differences between this version and the Version of Record. Please cite this article as doi: 10.1111/ceo.13188

This article is protected by copyright. All rights reserved. 
supported by a NHMRC Career Development Fellowship (\#1090466). The PhD student, Joshua Foreman is supported by an Australian Postgraduate Award scholarship.

\section{ABSTRACT}

Importance: Choroidal nevi are a common incidental finding on fundus examination. The National Eye Health Survey (NEHS, 2015-16) provides an up-todate estimate of the prevalence of choroidal nevi in non-Indigenous and Indigenous Australian adults.

Background: To describe the prevalence and characteristics of choroidal nevi amongst non-Indigenous and Indigenous Australian adults.

Design: Population-based cross-sectional study

Participants: This study included 3098 non-Indigenous Australians (aged 50-98 years) and 1738 Indigenous Australians (aged 40-92 years) living in 30 randomly selected sites, stratified by remoteness.

Methods: Choroidal nevi were graded from retinal photographs using standard protocols.

Main outcome measure: Prevalence of choroidal nevi

Results: In the non-Indigenous population aged 50 years and over, the weighted prevalence of choroidal nevi was $2.1 \%$ (95\% CI: 1.4, 3.3). Among Indigenous Australians aged 40 years and over, the weighted prevalence of choroidal nevi was 0.68\% (95\% CI: 0.4, 1.3). The average maximum diameter, surface area and distance from the disc of the choroidal nevi was $1730 \mu \mathrm{m}, 2,766,800 \mu \mathrm{m}^{2}$ and $3400 \mu \mathrm{m}$, respectively. After multivariate adjustments, Indigenous participants (OR = $0.28, p=0.01)$ and those of older age $(O R=0.79$ per 10 years, $p=0.02)$ were less 
likely to have choroidal nevi. Choroidal nevus was not the primary cause of vision loss in any participant.

Conclusions and relevance: Choroidal nevi were relatively infrequent amongst NEHS participants, however non-Indigenous Australians had a significantly higher prevalence than Indigenous Australians. Choroidal nevi did not affect visual acuity and the majority were small.

Key words: Choroidal nevi, epidemiology 


\section{INTRODUCTION}

Choroidal nevi are a common incidental finding on fundus examination, most frequently appearing as discrete oval or round lesions of increased choroidal pigment. ${ }^{1,2}$ While the majority of cases are benign, the clinical significance of choroidal nevi relates to their association with reduced vision when foveal in location and the rare potential for malignant transformation in approximately 1 in 4300-8845 cases. $^{3-6}$

The majority of data on the prevalence of choroidal nevi comes from clinical-based studies, with a wide variation in reported rates $(0.2 \%$ to $30 \%)$ that is likely attributable to differences in study populations and grading methods employed. ${ }^{1,4,7-9}$ Internationally, there have been few previous population-based estimates of the prevalence of choroidal nevi, ${ }^{10-12}$ with rates ranging from $1.4 \%$ in the Singapore Malay Eye Study ${ }^{12}$ to $4.1 \%$ in Caucasians in the Multi-Ethnic Study of Atherosclerosis (MESA). ${ }^{10}$ In Australia, a population-based study conducted in the early 1990's, the Blue Mountains Eye Study (BMES), reported the prevalence of choroidal nevi to be $6.5 \%$ in the non-Indigenous population. ${ }^{2}$ To our knowledge, no data on the epidemiology of choroidal nevi in Indigenous Australians currently exists. As ethnic variations in the prevalence of choroidal nevi have been reported, ${ }^{10,12}$ an understanding of the population-based prevalence in Indigenous Australians is warranted.

The purpose of this report is to describe the prevalence and characteristics of choroidal nevi in non-Indigenous and Indigenous Australian adults recruited from 30 geographic areas across Australia as part of the National Eye Health Survey (NEHS).

\section{METHODS}

Study population and general assessments 
The NEHS is a population-based, cross-sectional survey of Indigenous Australians aged 40 years or older and non-Indigenous Australians aged 50 years or older, conducted between March 2015 and April 2016. Details of the NEHS design and methodology have been described in detail elsewhere. ${ }^{13,14}$ In brief, multistage random-cluster sampling was used to select thirty Australian sites across five Remoteness Areas (Major City, Inner Regional, Outer Regional, Remote and Very Remote) based on data from the 2011 Australian Census. ${ }^{15}$ Participants were recruited door-to-door and an overall examination rate of $71.5 \%$ was achieved. The protocol was approved by the Royal Victorian Eye and Ear Hospital Human Research Ethics Committee (HREC-14/1199H) as well as state-based Indigenous organisations. Study procedures adhered to the tenets of the Declaration of Helsinki as revised in 2013 and participants provided written informed consent to participate. Socio-demographic data including age, gender, Indigenous status, ethnicity, years of education, language spoken at home, utilisation of eye health services, as well as medical and ocular histories were collected via an interviewer-administered questionnaire. Presenting distance visual acuity (VA) was measured in each eye using a logMAR chart (Brien Holden Vision Institute, Australia) in well-lit room conditions. Pinhole testing was performed on participants with visual acuity worse than $6 / 12$ in one or both eyes, followed by automated refraction (Nidek ARK-30 Type-R Hand-held auto-refractor/keratometer, Nidek Co., LTD, Japan) if VA improved to $6 / 12$ or better in either eye.

Retinal photography and nevus grading

Two standard 45 degree colour retinal images were taken of each eye, one of the optic disc and the other of the macula, using a digital retinal camera (Digital Retinography System, CenterVue SpA, Italy). Photography was repeated following pupil dilatation (tropicamide $0.5 \%$ ) when retinal images were of reduced quality due to small pupil size. Trained retinal graders from the Centre for Eye Research 
Australia masked to the identity and clinical characteristics of study participants graded fundus photographs for choroidal nevus and other retinal disease.

A choroidal nevus was defined using the same definition as previous populationbased studies. ${ }^{2,12}$ That is, an unequivocal pigmented slate blue or green-grey choroidal lesion measuring at least $500 \mu \mathrm{m}$ in diameter. Choroidal lesions resembling nevi that were partially depigmented were graded as patchy hypomelanotic nevi. Once identified, further analysis was conducted to determine; the shape (oval, round, or irregular) and colour (slate blue, green-grey, hypomelanotic, amelanotic or brown) of the nevi, number of nevi, position relative to the fovea (subfoveolar, subfoveal, macular, or extramacular), proximity of posterior margin to the optic disc, quadrant distribution relative to the optic disc and the presence of overlying drusen or other pigment. ${ }^{2,12}$ Nevus diameter, surface area and distance to the posterior margin of the optic disc were measured using Image] software (developed at the National Institute of Health) after carefully setting the image scale factor.

\section{Statistical Analysis}

Participants' demographics and baseline characteristics were summarised by the mean and standard deviation (SD) for normally distributed continuous data, or median and inter-quartile range for skewed data, and counts and percentages for categorical data. Data were weighted by calculating sample weights for all records using the probability of selection at each stage of sampling. Ninety-five percent confidence intervals (CI), taking into account the sampling design, were calculated for the prevalence of choroidal nevi. Univariate and multivariable logistic regression models were used to examine the associations between presence of choroidal nevi and key explanatory variables. Key explanatory variables included age, gender, ethnicity, years of education, language spoken at home and remoteness.

All probabilities quoted are two-sided and all statistical analyses were undertaken using Stata version 14.2 (StataCorp, College Station, TX). 


\section{RESULTS}

The study sample of the NEHS consisted of 3098 non-Indigenous and 1738 Indigenous Australians. Of these, 3010 (97\%) non-Indigenous and 1682 Indigenous (97\%) participants had retinal photographs in at least one eye that were gradable for choroidal nevus (gradable images in only one eye $=4.3 \%, 202 / 4692$ ). The mean age of the non-Indigenous and Indigenous study populations were 66.4 years [standard deviation $(S D)=9.6$ ] (58.9\% female) and 54.8 years $(S D=9.9)(53.7 \%$ female), respectively.

\section{Prevalence and characteristics of choroidal nevus}

In the non-Indigenous population aged 50 years and over, the weighted prevalence of choroidal nevi was 2.1\% (95\% CI: 1.4, 3.3) (Table 1). Among Indigenous Australians aged 40 years and over, the weighted prevalence of choroidal nevi was $0.68 \%(95 \% \mathrm{CI}: 0.4,1.3)$. Bilateral choroidal nevi were present in two nonIndigenous participants and no Indigenous participant. Two choroidal nevi were present in five eyes of five non-Indigenous participants and one eye of an Indigenous participant. Choroidal nevi were found in $2.8 \%$ of males and $1.6 \%$ of females in the non-Indigenous population ( $p=0.09$ ). Among Indigenous Australians aged 40 years and over, the prevalence of choroidal nevi was $0.71 \%$ for males and $0.66 \%$ for females $(p=0.93$ ). Of the 79 eyes with a choroidal nevus, only 2 had vision loss (best-corrected VA of <6/12). However, in both cases, the choroidal nevus was not the primary cause of vision loss.

The average maximum diameter, surface area and distance from the disc of the choroidal nevi was $1730 \mu \mathrm{m}, 2,766,800 \mu \mathrm{m}^{2}$ and $3400 \mu \mathrm{m}$, respectively. Of the 73 nevi found in 68 non-Indigenous participants, $81.6 \%$ were oval or round, $58.9 \%$ were green-grey, $52.1 \%$ were outside the macular and $9.6 \%$ were touching the disc (Table 2). Among the 12 nevi found in 11 Indigenous participants, $83.3 \%$ of nevi 
were oval or round, $50 \%$ were green-grey and none were sub-foveolar in location. Drusen were found on the surface of $17.8 \%$ of nevi in the non-Indigenous population and $8.3 \%$ of nevi in the Indigenous population.

Table 1: Crude and weighted prevalence of choroidal nevus by Indigenous status, age and gender

\begin{tabular}{lccc}
\hline & n & $\begin{array}{c}\text { Crude } \\
\text { \% }(\mathbf{9 5 \%} \mathbf{~ C I})\end{array}$ & $\begin{array}{c}\text { Weighted } \\
\text { \% }(\mathbf{9 5 \%} \mathbf{C I})\end{array}$ \\
\hline $\begin{array}{l}\text { Non- } \\
\text { Indigenous }\end{array}$ & & & \\
Female & 23 & $1.4(0.09,2.1)$ & $1.6(0.7,0.3)$ \\
Male & 43 & $3.1(2.2,4.1)$ & $2.8(1.4,3.3)$ \\
Age & & & \\
$50-59$ & 27 & $3.4(2.2,4.9)$ & $3.3(2.0,5.4)$ \\
$60-69$ & 21 & $1.8(1.1,2.8)$ & $1.7(0.92,2.9)$ \\
$70-79$ & 16 & $2.2(1.3,3.5)$ & $2.1(1.1,3.9)$ \\
$80+$ & 2 & $0.61(0.07,2.2)$ & $0.98(0.23,4.1)$ \\
Total & 66 & $2.2(1.7,2.8)$ & $2.1(1.4,3.3)$ \\
\hline Indigenous & & & \\
Female & 4 & $0.5(1.6,1.2)$ & $0.66(0.28,1.5)$ \\
Male & 7 & $0.9(0.3,1.9)$ & $0.71(0.20,2.5)$ \\
Age & & & \\
$40-49$ & 1 & $0.17(0.04,0.97)$ & $0.18(0.02,1.4)$ \\
$50-59$ & 4 & $0.65(0.18,1.7)$ & $0.64(0.23,1.8)$ \\
$60-69$ & 4 & $1.2(0.32,3.0)$ & $1.0(0.32,3.1)$ \\
$70+$ & 2 & $1.3(1.6,4.8)$ & $1.9(0.54,6.5)$ \\
Total & 11 & $0.59(0.29,1.1)$ & $0.68(0.35,1.3)$ \\
\hline
\end{tabular}

Table 2: Characteristics of choroidal nevi in non-Indigenous and Indigenous Australians

\begin{tabular}{lcc}
\hline & \multicolumn{2}{c}{ Choroidal Nevi, No. (\%) } \\
Characteristic & $\begin{array}{c}\text { Non-Indigenous } \\
(n=73)\end{array}$ & Indigenous $(\mathrm{n}=$ \\
\hline
\end{tabular}




\begin{tabular}{lcc}
\hline Diameter (mm) & $13(17.8)$ & $2(16.7)$ \\
$0-1$ & $40(54.8)$ & $8(66.6)$ \\
$1-2$ & $20(27.4)$ & $2(16.7)$ \\
$>2$ & & \\
Shape & $32(43.8)$ & $4(33.3)$ \\
Oval & $28(38.4)$ & $6(50.0)$ \\
Round & $13(17.8)$ & $2(16.7)$ \\
Irregular & $24(32.9)$ & $2(16.7)$ \\
Color & $43(58.9)$ & $8(66.6)$ \\
Slate blue & $2(2.7)$ & $1(8.3)$ \\
Green-gray & $4(5.5)$ & $1(8.3)$ \\
Hypomelanotic & $1(1.4)$ & \\
Brown & $7(9.6)$ & $0(0.0)$ \\
Position & $27(36.9)$ & $4(3.3)$ \\
Subfoveolar & $38(52.1)$ & $7(58.3)$ \\
Subfoveal & $7(9.6)$ & $2(16.6)$ \\
Macular & & \\
Extramacular & & \\
Posterior margin & & \\
touching disc & $81(28.8)$ & $2(16.7)$ \\
Quadrant relative to & $8(10.9)$ & $5(41.7)$ \\
optic disc & $34(46.6)$ & $5(41.7)$ \\
Upper temporal & $10(13.7)$ & $0(0.0)$ \\
Upper nasal & $13(17.8)$ & $1(8.3)$ \\
Lower temporal & $1(1.4)$ & $0(0.0)$ \\
Lower nasal & & \\
Drusen present & & \\
Other pigment present & &
\end{tabular}

Due to the low frequency of choroidal nevi in Indigenous Australians, Indigenous and non-Indigenous data were combined in logistic regression analysis examining associations between choroidal nevi and selected characteristics (Table 3). After controlling for all variables in the model (model 1$)$, Indigenous participants (OR = $0.25, p=0.005$ ) were less likely to have choroidal nevi. When adjusting for only variables identified as $p<0.10$ in the univariate analysis (model 2 ), Indigenous participants $(O R=0.28, p=0.01)$ and those of older age $(O R=0.79$ per 10 years, $p=0.02$ ) were less likely to have choroidal nevi. 
Table 3: Relationship between choroidal nevus and selected characteristics in Australians $(n=4692)$

\begin{tabular}{|c|c|c|c|c|c|c|}
\hline & \multicolumn{2}{|c|}{ Univariate } & \multicolumn{2}{|c|}{ Multivariable $^{1}$} & \multicolumn{2}{|c|}{ Multivariable $^{2}$} \\
\hline & $\begin{array}{l}\text { OR [ 95\% } \\
\text { (CI)] }\end{array}$ & $\mathbf{p}$ & $\begin{array}{l}\text { OR [ } 95 \% \\
\text { (CI)] }\end{array}$ & $\mathbf{p}^{*}$ & $\begin{array}{l}\text { OR [ 95\% } \\
\text { (CI)] }\end{array}$ & $\mathbf{p}^{*}$ \\
\hline Indigenous & $\begin{array}{c}0.31(0.14, \\
0.71)\end{array}$ & 0.01 & $\begin{array}{c}0.25(0.10 \\
0.63)\end{array}$ & 0.01 & $\begin{array}{c}0.28(0.11 \\
0.73)\end{array}$ & 0.01 \\
\hline $\begin{array}{l}\text { Age (per } 10 \\
\text { years) }\end{array}$ & $\begin{array}{c}0.80(0.67 \\
0.96)\end{array}$ & 0.02 & $\begin{array}{c}0.81(0.63 \\
1.05)\end{array}$ & 0.11 & $\begin{array}{c}0.79(0.66 \\
0.96)\end{array}$ & 0.02 \\
\hline Gender (male) & $\begin{array}{c}1.84(0.89 \\
3.80)\end{array}$ & 0.10 & $\begin{array}{c}1.93(0.88 \\
4.26)\end{array}$ & 0.10 & $\begin{array}{c}1.99(0.92 \\
4.29)\end{array}$ & 0.08 \\
\hline Education (year) & $\begin{array}{c}1.04(0.99 \\
1.10)\end{array}$ & 0.12 & $\begin{array}{c}1.03(0.97 \\
1.10)\end{array}$ & 0.31 & & \\
\hline $\begin{array}{l}\text { English spoken } \\
\text { at home }\end{array}$ & $\begin{array}{c}2.84(0.34 \\
(23.62)\end{array}$ & 0.32 & $\begin{array}{c}1.18(0.09 \\
15.33)\end{array}$ & 0.89 & & \\
\hline $\begin{array}{l}\text { Ethnicity } \\
\text { Oceanian }\end{array}$ & 1 & & 1 & & & \\
\hline European & $\begin{array}{c}0.45(0.18 \\
1.17)\end{array}$ & 0.10 & $\begin{array}{c}0.48(0.19 \\
1.19)\end{array}$ & 0.11 & & \\
\hline Others & $\begin{array}{c}0.22(0.03 \\
1.64)\end{array}$ & 0.13 & $\begin{array}{c}0.24(0.02 \\
2.62)\end{array}$ & 0.23 & & \\
\hline Remoteness & & & & & & \\
\hline Major City & 1 & & 1 & & & \\
\hline Inner Regional & $\begin{array}{c}1.46(0.49 \\
4.31)\end{array}$ & 0.48 & $\begin{array}{c}1.38(0.47 \\
4.03)\end{array}$ & 0.54 & & \\
\hline Outer Regional & $\begin{array}{c}0.89(0.38 \\
2.10)\end{array}$ & 0.78 & $\begin{array}{c}0.86(0.37 \\
1.99)\end{array}$ & 0.71 & & \\
\hline Remote & $\begin{array}{c}1.63(0.79 \\
3.34)\end{array}$ & 0.18 & $\begin{array}{c}1.54(0.75 \\
3.17)\end{array}$ & 0.23 & & \\
\hline Very Remote & $\begin{array}{c}0.59(0.20 \\
1.76)\end{array}$ & 0.33 & $\begin{array}{c}0.55(0.24 \\
1.27)\end{array}$ & 0.16 & & \\
\hline $\begin{array}{l}\text { Self-reported } \\
\text { diabetes }\end{array}$ & $\begin{array}{c}0.45(0.18 \\
1.12)\end{array}$ & 0.08 & $\begin{array}{c}0.49(0.18 \\
1.31)\end{array}$ & 0.15 & $\begin{array}{c}0.45(0.05 \\
1.21)\end{array}$ & 0.13 \\
\hline $\begin{array}{l}\text { Self-reported } \\
\text { stroke }\end{array}$ & $\begin{array}{c}0.23(0.05 \\
1.08)\end{array}$ & 0.06 & $\begin{array}{c}0.25(0.05 \\
1.17)\end{array}$ & 0.08 & $\begin{array}{c}0.26(0.05 \\
1.21)\end{array}$ & 0.08 \\
\hline
\end{tabular}


$\mathrm{OR}=$ Odds ratio; $\mathrm{CI}=$ Confidence interval; $*$ Statistical significance was set as a $\mathrm{p}$ value of $\leq 0.05$ (two tailed) ${ }^{1}$ full model; ${ }^{2}$ reduced model, which included only $\mathrm{p}<0.10$ in the univariate logistic regression model.

\section{DISCUSSION}

This paper presents the prevalence of choroidal nevi in a population-based, national sample of non-Indigenous and Indigenous Australian adults. The weighted prevalence of choroidal nevi was $2.1 \%$ in non-Indigenous Australians aged 50 years and over and $0.68 \%$ in Indigenous Australians aged 40 years and over. In line with previous population-based reports, ${ }^{2,10,12}$ there was a trend towards a decreasing prevalence of choroidal nevi with increasing age.

The clinical relevance of choroidal nevus relates to the rare transformation to melanoma. Nevi of diameter $>6 \mathrm{~mm}, 1-3 \mathrm{~mm}$ in elevation ${ }^{1,16,17}$ and/or with the posterior margin bordering the optic disc ${ }^{18}$ have been identified as particularly suspicious in previous literature. Furthermore, while overlying drusen is often suggestive of lesion chronicity, ${ }^{16,19}$ there is some evidence that it may be associated with nevus growth. ${ }^{2}$ In the present study, the majority of nevi were small (mean diameter $=1.75 \mathrm{~mm}$ ) and the largest lesion measured $5.77 \mathrm{~mm}$ in diameter. A total of $9.6 \%(7 / 73)$ and $16.6 \%(2 / 12)$ of nevi were touching the optic disc in the nonIndigenous and Indigenous population, respectively. This is higher than that reported in the BMES $(6.1 \%){ }^{2}$ the Singapore Malay Eye Study $(0 \%)^{12}$ and the MESA $(4.3 \%) .{ }^{10}$ In the non-Indigenous population, we found that $17.8 \%(13 / 73)$ of nevi had overlying drusen, similar to the Singapore Malay Eye Study $(20 \%)^{12}$ and the MESA $(24.8 \%)^{10}$ but substantially lower than the BMES (98\%). ${ }^{2}$ The BMES employed stereoscopic fundus photography and therefore it is possible that their finer grading system may have contributed to this finding. 
When compared to previous international studies, the prevalence of choroidal nevi in non-Indigenous Australians (2.1\%) in the NEHS was lower than that reported in Beijing Eye Study $(2.9 \%){ }^{11}$ similar to the MESA $(2.1 \%)^{10}$ and higher than the Singapore Malay Eye Study $(1.4 \%){ }^{12}$ Of note, we report a markedly lower prevalence than that found in non-Indigenous Australians in the BMES $(6.5 \%){ }^{2}$ Differences in the retinal photography methods employed in the present study and the BMES are likely to be contributory as the latter study employed 6-field, 30degree stereoscopic fundus photography. Previous research estimates that $25 \%$ of nevi would likely be missed on 2-field photography, ${ }^{12,20}$ and as such we acknowledge that by not employing a wider photographic field, it is likely that the present study underestimated the prevalence of choroidal nevi. Interestingly, while the mean nevus diameter in the NEHS was larger than that found in the BMES (NEHS $=1.75 \mathrm{~mm}$ vs. BMES $=1.25 \mathrm{~mm}$ ), other characteristics of nevi were similar including shape (round or oval; NEHS $=82 \%$ vs. BMES $=75 \%$ ), position (lower temporal; NEHS $=47 \%$ vs. $\mathrm{BMES}=45 \%$ ) and colour (blue-grey; $\mathrm{NEHS}=92 \%$ vs. $\mathrm{BMES}=87 \%$ ).

To our knowledge, this is the first population-based study to examine the prevalence and characteristics of choroidal nevi in Indigenous Australians. After adjusting for age and other potential confounders, we report that Indigenous Australian adults were approximately $75 \%$ less likely to display a choroidal nevi compared to nonIndigenous Australians. Previous research has suggested a difference in the prevalence of choroidal nevi between Caucasian populations and those of other ethnicities. ${ }^{10,12}$ For example, the MESA ${ }^{10}$ reported very low frequencies of choroidal nevi among African American (0.7\%) and Hispanics (1.2\%) compared to Caucasians $(4.1 \%)$ in the same cohort. These findings are in line with previous studies that have reported nevi of the skin and iris are more common in Caucasians. ${ }^{21-24}$ Furthermore, differences in fundus pigmentation between Indigenous and non-Indigenous Australians should also be taken into account, where it is easier to detect a choroidal 
nevus in the more pale, non-Indigenous fundi. Of interest, anatomic features of choroidal nevi including size, colour and position were similar amongst Indigenous and non-Indigenous Australians.

Similarly to the BMES, ${ }^{2} \mathrm{MESA}^{10}$ and the Singapore Malay Eye Study, ${ }^{12}$ there was a trend towards a decreasing prevalence of choroidal nevi with increasing age in nonIndigenous participants in the NEHS. That is, the prevalence was over 3-fold higher in those $50-59$ years old (3.3\%) compared to those aged $80+$ years $(0.98 \%)$. As with previous studies, there is no obvious explanation for the age differences in the prevalence of choroidal nevi, however this finding may be partly explained by the established relationship between age and image gradability, ${ }^{25}$ where a decreasing media clarity in the older age groups may have led to a detection bias. Furthermore, a relatively small representation of the oldest age group in the sample may have resulted in an unstable estimate of choroidal nevi in this group.

The strengths of this study include the national population-based design, stratification by Indigenous status and the use of a standardised protocol to grade for choroidal nevi. The principal limitation includes the use of non-stereoscopic images in only two fields of view which is likely to have led to an underestimation of the prevalence of choroidal nevi. However, this is unlikely to have influenced comparisons of prevalence amongst non-Indigenous and Indigenous participants in this study. Furthermore, a small proportion of participants had gradable images for only one eye $(4.3 \%, 202 / 4692)$ which may have also led to an underestimation in the prevalence.

In summary, we report the prevalence of choroidal nevi to be $2.1 \%$ in nonIndigenous Australian adults, and even more infrequent amongst Indigenous Australian adults $(0.68 \%)$. Choroidal nevi did not affect visual acuity and nevus 
characteristics were largely comparable to the few previous population-based reports in Caucasian, Asian and multi-ethnic cohorts.

\section{Acknowledgements}

The Centre for Eye Research Australia (CERA) and Vision 2020 Australia wish to recognise the contributions of all the NEHS project steering committee members (Professor Hugh Taylor, Dr Peter van Wijngaarden, Jennifer Gersbeck, Dr Jason Agostino, Anna Morse, Sharon Bentley, Robyn Weinberg, Christine Black, Genevieve Quilty, Louis Young and Rhonda Stilling) and the core CERA research team who assisted with the survey field work (Joshua Foreman, Pei Ying Lee, Rosamond Gilden, Larissa Andersen, Benny Phanthakesone, Celestina Pham, Alison Schokman, Megan Jackson, Hiba Wehbe, John Komser and Cayley Bush). Furthermore, we would like to acknowledge the overwhelming support from all collaborating Indigenous organisations who assisted with the implementation of the survey, and the Indigenous health workers and volunteers in each survey site who contributed to the field work. 


\section{REFERENCES}

1. Gass JD. Problems in the differential diagnosis of choroidal nevi and malignant melanoma. XXXIII Edward Jackson Memorial lecture. Transactions Section on Ophthalmology American Academy of Ophthalmology and Otolaryngology 1977; 83(1): 19-48.

2. Sumich $P$, Mitchell $P$, Wang JJ. Choroidal nevi in a white population: the Blue Mountains Eye Study. Arch Ophthalmol 1998; 116(5): 645-50.

3. Albert DM, Lahav M, Packer S, Yimoyines D. Histogenesis of malignant melanomas of the uvea. Occurrence of nevus-like structures in experimental choroidal tumors. Arch Ophthalmol 1974; 92(4): 318-23.

4. Ganley JP, Comstock GW. Benign nevi and malignant melanomas of the choroid. Am J Ophthalmo/ 1973; 76(1): 19-25.

5. Naumann G, Yanoff M, Zimmerman LE. Histogenesis of malignant melanomas of the uvea. I. Histopathologic characteristics of nevi of the choroid and ciliary body. Arch Ophthalmol 1966; 76(6): 784-96.

6. Singh $A D$, Kalyani $P$, Topham A. Estimating the risk of malignant transformation of a choroidal nevus. Ophthalmology 2005; 112(10): 1784-9.

7. Albert DM, Searl SS, Forget B, Lavin PT, Kirkwood J, Nordlund JJ. Uveal findings in patients with cutaneous melanoma. Am J Ophthalmo/ 1983; 95(4): 4749.

8. Lang GK, Daumann FJ. [Peripheral fundus changes in subjects with healthy eyes (pilots)]. Klinische Monatsblatter fur Augenheilkunde 1982; 181(6): 493-5. 9. Smith RE, Ganley JP. Ophthalmic survey of a community. 1. Abnormalities of the ocular fundus. Am J Ophthalmol 1972; 74(6): 1126-30.

10. Greenstein MB, Myers CE, Meuer SM, et al. Prevalence and characteristics of choroidal nevi: the multi-ethnic study of atherosclerosis. Ophthalmology 2011;

118(12): 2468-73. 
11. Jonas JB, You QS, Xu L, Wang YX. Choroidal nevi in adult chinese. Ophthalmology 2008; 115(6): 1102-.e1.

12. $\mathrm{Ng} \mathrm{CH}$, Wang JJ, Mitchell $\mathrm{P}$, Amirul Islam FM, Wong TY. Prevalence and characteristics of choroidal nevi in an Asian vs white population. Arch Ophthalmol 2009; 127(3): 314-9.

13. Foreman J, Keel S, Dunn R, van Wijngaarden P, Taylor HR, Dirani M. Sampling methodology and site selection in the National Eye Health Survey: an Australian population-based prevalence study. Clinical \& experimental ophthalmology 2017; 45(4): 336-47.

14. Foreman J, Keel S, van Wijngaarden P, Taylor HR, Dirani M. Recruitment and Testing Protocol in the National Eye Health Survey: A Population-Based Eye Study in Australia. Ophthalmic Epidemio/2017: 1-11.

15. ABS. Australian Statistical Geography Standard (ASGS). 20142014. http://www.abs.gov.au/websitedbs/D3310114.nsf/home/Australian+Statistical+Geog raphy+Standard+(ASGS).

16. Butler $\mathrm{P}, \mathrm{Char} \mathrm{DH}$, Zarbin $\mathrm{M}$, Kroll $\mathrm{S}$. Natural history of indeterminate pigmented choroidal tumors. Ophthalmology 1994; 101(4): 710-6; discussion 7. 17. Mims JL, 3rd, Shields JA. Follow-up studies of suspicious choroidal nevi. Ophthalmology 1978; 85(9): 929-43.

18. Shields CL, Cater J, Shields JA, Singh AD, Santos MC, Carvalho C. Combination of clinical factors predictive of growth of small choroidal melanocytic tumors. Arch Ophthalmo/ 2000; 118(3): 360-4.

19. Li HK, Shields CL, Mashayekhi A, et al. Giant choroidal nevus clinical features and natural course in 322 cases. Ophthalmology 2010; 117(2): 324-33.

20. Naumann G, Hellner K, Naumann L. Pigmented nevi of the choroid: clinical study of secondary changes in the overlying tissues. . Trans Am Acad Ophthalmol Otolaryngol 1971; 75: 110-23. 
21. Cormier JN, Xing $Y$, Ding $M$, et al. Ethnic differences among patients with cutaneous melanoma. Arch Intern Med 2006; 166(17): 1907-14.

22. Margo CE, Mulla Z, Billiris K. Incidence of surgically treated uveal melanoma by race and ethnicity. Ophthalmology 1998; 105(6): 1087-90.

23. Neugut AI, Kizelnik-Freilich S, Ackerman C. Black-white differences in risk for cutaneous, ocular, and visceral melanomas. American journal of public health 1994; 84(11): 1828-9.

24. Tsai T, Vu C, Henson DE. Cutaneous, ocular and visceral melanoma in African Americans and Caucasians. Melanoma research 2005; 15(3): 213-7.

25. Scanlon PH, Foy C, Malhotra R, Aldington SJ. The influence of age, duration of diabetes, cataract, and pupil size on image quality in digital photographic retinal screening. Diabetes Care 2005; 28(10): 2448-53. 


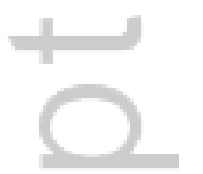

4 


\section{University Library}

\section{- M M N E R VA A gateway to Melbourne's research publications}

Minerva Access is the Institutional Repository of The University of Melbourne

Author/s:

Keel, S;Xie, J;Foreman, J;Taylor, HR;Dirani, M

Title:

Prevalence and characteristics of choroidal nevi: the Australian National Eye Health Survey

Date:

2018-09-01

Citation:

Keel, S., Xie, J., Foreman, J., Taylor, H. R. \& Dirani, M. (2018). Prevalence and

characteristics of choroidal nevi: the Australian National Eye Health Survey. CLINICAL AND EXPERIMENTAL OPHTHALMOLOGY, 46 (7), pp.777-782. https://doi.org/10.1111/ceo.13188.

Persistent Link:

http://hdl.handle.net/11343/283668 